

S. N. Koyal

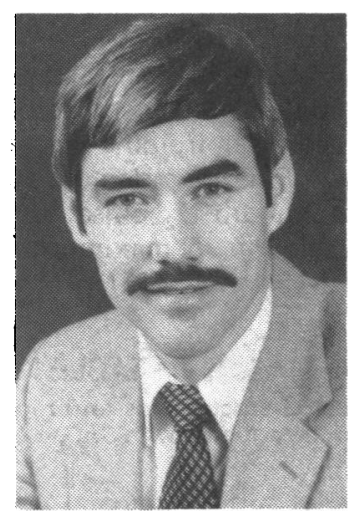

R. J. Stuart

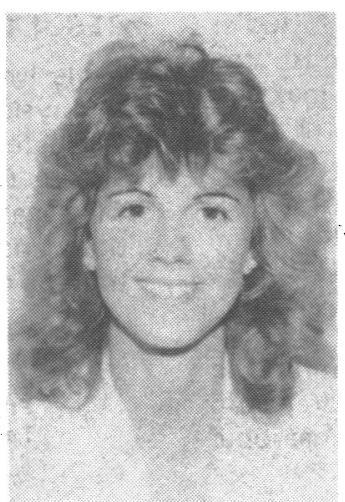

Ruth Lundstrom

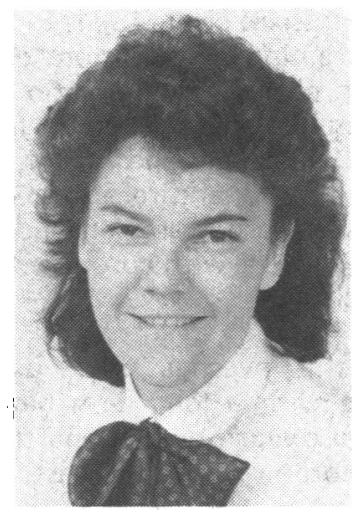

V. Kraemer (Mrs. LaV. Thomas)



M. H. Ellestad

\title{
DOES EXERCISE ALTER ANAEROBIC THRESHOLD IN CORONARY ARTERY DISEASE DURING BETA BLOCKADE?
}

\author{
S. N. KOYAL, PhD, FACSM, R. J. STUART, MD, Ruth LUNDSTROM, MS, RPT, V. THOMAS, BA \\ and M. H. ELLESTAD, MD, FACC
}

\begin{abstract}
Division of Cardiology, Memorial Medical Center of Long Beach (University of California - Irvine), 2801 Atlantic Avenue, Long Beach, California $90801-1428$
\end{abstract}

\begin{abstract}
The effect of propanolol on cardiac patients undergoing exercise training is reported to increase exercise tolerance and maximum oxygen uptake $\left(\mathrm{VO}_{2} \max \right)$ but its effect on anaerobic threshold (AT) is unknown. It was the purpose of this study to determine the role of exercise training with propanolol on AT in patients with coronary artery disease (CAD). Eight men and one woman with significant (CAD) were selected for this study. Each patient completed a maximum treadmill stress test (MTST) following the Bruce protocol on propanolol $40.160 \mathrm{mg} / \mathrm{day}$ as a control study. Cardiorespiratory variables were measured at rest and at each stage of the treadmill test. These patients underwent an exercise training programme for 12.16 weeks on the same dose of propanolol. Training sessions were for a minimum of 30-40 minutes, 3 times a week, with training heart rate of $75 \%-85 \%$ of the pretraining peak heart rate. Training heart rate ranged from 98 to 128 beats/min. They were retested with a MTST after the training programme, on the same dose of propanolol. AT was calculated noninvasively by measuring respiratory variables every 30 seconds in relation to work increment. AT was identified by measuring the time course of $\mathrm{VE}, \mathrm{VCO}, \mathrm{VE} / \mathrm{VO} \mathrm{O}_{2}$, etc. in relation to incremental work. The mean values of $\mathrm{VO}_{2}, \mathrm{O}_{2} \mathrm{P}$ and $\% \mathrm{VO}_{2} \max$ at $\mathrm{AT}$ before and after training on propanolol were as follows: $\mathrm{VO} \mathrm{O}_{2}=1.43$ $\mathrm{L} / \mathrm{min} \pm .25$ and $1.86 \mathrm{~L} / \mathrm{min} \pm .44, \mathrm{O}_{2} \mathrm{P}=14.35 \pm 2.40$ and $18.73 \pm 4.00 \mathrm{ml} / \mathrm{beat}, \%$ of $\mathrm{VO}_{2} \max =68.20 \pm 6.31$ and $73.59 \pm 5.84$ The mean changes of $\mathrm{VO}_{2} \mathrm{O}_{2} \mathrm{P}$, and $\%$ of $\mathrm{VO}_{2} \max$ were $+0.43 \mathrm{~L} / \mathrm{min} \pm 0.20(\mathrm{P}<.003),+4.38 \pm 2.55(\mathrm{P}<0.03)$ and $\pm 5.07 \% \pm$ $4.84(\mathrm{P}<.001)$. After exercise training on propanolol, the mean peak exercise tolerance time and absolute $\mathrm{VO}_{2}$ max increased by $2.8 \mathrm{~min}$ (from 9.0 to $11.8 \mathrm{~min})(P<.001)$ and $22.7 \%(P<.007)$, respectively. We conclude that the increase in anaerobic threshold in patients with coronary artery disease may be due to improvement in $\mathrm{VO}_{2}$ max, increased stroke volume, and peripheral $\mathrm{O}_{2}$ extraction.
\end{abstract}

Key words: Coronary artery disease, Exercise training, Propanolol, Anaerobic threshold, Maximum oxygen uptake, Oxygen pulse, Minute ventilation, Ventilatory equivalents.

\section{INTRODUCTION}

The use of beta adrenergic blocking agents like propanolol is well established in the treatment of symptomatic patients with coronary artery disease. Propanolol reduces blood pressure and heart rate during physical or emotional stress. Controversy however, has developed regarding the effect of propanolol on cardiovascular training.

The adequacy of circulatory and metabolic responses to exercise in man can be described by the determination of maximum oxygen uptake $\left(\mathrm{VO}_{2} \max \right)$ and other cardiorespiratory variables; e.g. cardiac output, blood pressure, $\mathrm{O}_{2}$ pulse, $\mathrm{CO}_{2}$ production and ventilatory equivalents for $\mathrm{O}_{2}$ and $\mathrm{CO}_{2}$.

Address for correspondence and reprints:

Sankar Koyal, PhD

Division of Cardiology

Memorial Medical Center of Long Beach

P.O. Box 1428

Long Beach, California 90801, USA
In the normal subject, during a steady-state or progressive exercise test, there is an interaction between the cardiovascular and pulmonary system to meet the metabolic demands of working muscles. Energy sources for moderate levels of exercise, where oxygen demand is matched by oxygen supply, are usually derived from aerobic metabolism. With incremental exercise, oxygen delivery eventually becomes inadequate, and anaerobic metabolism occurs. At this point, anaerobic threshold (AT) is reached and accompanied by an increase in $\mathrm{VCO}_{2}$ and lactate production (Wasserman et al, 1973). With progressive work increments in exercise the observation of heart rate, blood pressure, electrocardiogram (ECG) and respiratory changes identify the time of onset of the anaerobic threshold. Respiratory parameters like minute ventilation (VE) gas exchange ratio, and ventilatory equivalents for oxygen and carbon dioxide also provide useful information for the detection of anaerobic threshold. A number of authors, Wasserman et al, 1973; Wasserman and Whipp, 1975; Davis et al, 1979; Matsumura et al, 1983, have defined anaerobic threshold as the level of work or oxygen consumption just below the point at which metabolic acidosis and other associated changes in 
gas exchange take place. Hossack et al, 1981, in their studies on propanolol on exercise training "prescription" demonstrated a minor but insignificant change in the ratio of maximal oxygen uptake to maximum heart rate. Contrary to Hossack et al, 1981; Obma et al, 1979; Thadani and Parker, 1979; Pratt et al, 1981; Vanhees et al, 1982; and recently Gordon et al, 1983, showed an improved cardiovascular and ventilatory responses after training in patients with coronary heart disease during beta-adrenergic blockade.

It was the purpose of this investigation to determine the effect of exercise training with a long term beta-adrenergic blocking agent on maximal oxygen uptake and the anaerobic threshold in patients with coronary artery disease.

\section{METHODS}

Eight ambulatory men and one woman with significant coronary artery disease, documented by angiographic study, were selected at random for this study from among patients attending our clinic. The physical characteristics of the patients were as follows: (a) their ages varied from 42 to 63 years with an average of $52.1 \pm 6.7$ yrs; (b) Height ranged from between 165 to $185 \mathrm{cms}$ with a mean height of $177.6 \pm 5.8 \mathrm{~cm}$ and (c) Body weight varied from 64 to $99 \mathrm{~kg}$ with an average weight of $82.8 \pm 11.4 \mathrm{~kg}$. Patients were receiving orally a nonselective beta adrenergic blocker - propanolol $40-160 \mathrm{mg} /$ day. It was started prior to the initial test and continued during maximal treadmill stress test for a 12-16 week period of cardiovascular training, and through the final treadmill stress test. The exercise training consisted of three sessions a week of walk/jog/run or cycle-ergometer exercise at a level of approximately $75 \%-85 \%$ of maximum exercise capacity demonstrated during the initial maximal treadmill test for a minimum of 30 minutes. A pre exercise warm-up of 15-20 minutes with stretching calisthenics preceded the formal cardiovascular training session and ended with a cool-down period of 10-15 minutes.

Before joining the cardiovascular training programme all patients underwent a maximum treadmill stress test following the Bruce protocol (Bruce et al, 1963) while on their usual dose of propanolol. Oxygen uptake and other cardiorespiratory variables were continuously monitored by the Beckman Metabolic Cart (Beckman, Fullerton, CA). Cardiorespiratory variables such as oxygen uptake $\left(\mathrm{VO}_{2}\right)$, heart rate (HR), oxygen pulse $\left(O_{2} P\right)$, metabolic equivalent (mets), respiratory gas exchange ratio (RER), ventilatory equivalents for $\mathrm{O}_{2}$ and $\mathrm{CO}_{2}$ (VE) $\mathrm{VCO}_{2}$ and $\mathrm{VE} / \mathrm{VO}_{2}$ ), tidal volume, respiratory rate, ratio of respiratory dead space and tidal volume ratio (VD/VT) were measured and printed out at $30 \mathrm{~s}$ intervals at rest and during each stage of the treadmill exercise.

During the test, the patient had a rubber mouthpiece and nose clip, and was connected through a nonbreathing Rudolph valve (dead space $=110 \mathrm{ml}$ ). The expired air went through the mixing chamber into an assembly for measuring expired volume, breath counting, and measurement of expired air temperature. For all sampling conditions, a pump drew the sample through $\mathrm{O}_{2}$ and $\mathrm{CO}_{2}$ sensors at a nominal flow rate of $50 \mathrm{ml} / \mathrm{min}$. Although a mouthpiece is objectionable to some patients, the diagnostic value of gas exchange information justified its use. The loss of verbal communication with a subject during the test was overcome with prearranged hand signals. The ambient temperature of the laboratory in which the patients were tested was $22.4 \pm 1.5^{\circ} \mathrm{C}$.

Measurement of maximal oxygen uptake $\left(\mathrm{VO}_{2} \max \right)$ and other cardiorespiratory variables were repeated on each individual patient using an identical protocol after 12.16 weeks of supervised physical training.

\section{Determination of Anserobic Threshold}

Anaerobic threshold is defined as the level of workload or oxygen consumption just below the level at which metabolic acidosis occurs. AT is reached during graded workload when the level of lactic acid in blood just exceeds the levels found at rest or during light exercise.

The anaerobic threshold was determined non-invasively in each case by the method described by Wasserman et al, 1973; Davis et al, 1979 , Matsumura et al, 1983. By following the time course of minute ventilation (VE), carbon dioxide $\left(\mathrm{VCO}_{2}\right)$ endtidal $\mathrm{O}_{2}\left(\mathrm{ETO} \mathrm{O}_{2}\right)$, and ventilatory equivalent of oxygen ( $\left.V E / V_{2}\right)_{1}$, anaerobic threshold was identified as the first major inflection point where $\mathrm{VE} / \mathrm{NO}_{2}$ began to rise.

\section{Reproducibility of Anaerobic Threchold}

Four patients underwent maximum treadmill testing using the same protocol within 2-3 weeks. The mean difference of anaerobic threshold between the two tests was considered statistically insignificant. The reproducibility of AT was calculated as follows:

$$
\frac{\text { AT \#1-AT \#2 }}{\text { AT \#1 }} \times 100 \%
$$

The difference varied from: -4 to $+6 \%$.

\section{RESULTS}

Table I represents the mean values with the standard deviation of physical characteristics and responses to maximal treadmill test before and after training in patients with coronary artery disease (CAD). The data demonstrate a significant increase in $\mathrm{VO}_{2}$ max, maximum $\mathrm{O}_{2}$ pulse, absolute treadmill time (duration) and reduction in maximum heart rate before and after training of $12-16$ weeks.

\section{TABLE}

Physical characteristics and response to Max. Stress Test of the patients with CAD(before and after training regime)

\begin{tabular}{|c|c|c|c|c|}
\hline $\begin{array}{l}\text { yr) } \\
\text { it (CM) } \\
\text { it (Kg) } \\
\text { t rest (beats/min) } \\
\text { it rest (mm Hg) } \\
\text { it rest (mm Hg) } \\
\text { H.R. (beats/min) } \\
\mathrm{O}_{2} \text { Pulse(ml/beat) } \\
\text { SBP } \\
\text { DBP } \\
\text { VO. (ml }\{\mathrm{Ka} \times \text { Min\}) }\end{array}$ & $\begin{array}{l}\text { Before } \\
2.1 \pm 6.75 \\
77.6 \pm 5.79 \\
2.8 \pm 11.45 \\
8 \pm 10.3 \\
15.0 \pm 15.04 \\
3.0 \pm 10.9 \\
31 \pm 18.9 \\
5.8 \pm 6.6 \\
55 \pm 16.0 \\
7 \pm 7.6 \\
4.57 \pm 6.34 \\
0 \pm 25\end{array}$ & $\begin{array}{l}.35 \\
8 \\
6 \\
.2 \\
.1 \\
.0 \\
.6 \\
4.87 \\
.5\end{array}$ & $\begin{array}{r}3.62 \\
9.7 \\
7.8 \\
2.7 \\
2.2 \\
25.3 \\
2.5 \\
6.5 \\
24.0\end{array}$ & $\begin{array}{l}04 \\
005 \\
02 \\
5 \\
5 \\
001 \\
5 \\
03 \\
002\end{array}$ \\
\hline
\end{tabular}

Table I Physical characteristics and response to maximum stress test of the patients with coronary artery disease before and after endurance training with propanolol.

\pm Standard deviation, $p=$ probability, $(P)=$ propanolol

Table II shows the individual data of maximum oxygen uptake $\left(\mathrm{VO}_{2} \max \right)$ before and after training with propanolol. The mean value of $\mathrm{VO}_{2}$ max rose significantly from 2.07 L/min. Standard temperature pressure dry (STPD) to 2.53 $\mathrm{L} / \mathrm{min}$ (STPD) (P < .007). Table III exhibits the individual oxygen uptake data of the patients at anaerobic threshold (AT) before and after training. The mean value of oxygen uptake at anaerobic threshold (AT) was $1.43 \mathrm{~L} / \mathrm{min}$ (STPD) before training which increased significantly to $1.86 \mathrm{~L} / \mathrm{min}$ $(\mathrm{P}<.003)$. The percentage of $\mathrm{VO}_{2} \max$ at anaerobic threshold (AT) of the individual patient, portrayed in Table IV, rose significantly from 68.20 to $73.59 \%$ after training with propanolol. The average patient's body weight decreased significantly with exercise training which was accompanied by an increase in mean value of $\mathrm{VO}_{2} \mathrm{max} / \mathrm{kg}$ body wt. $(\mathrm{P}<.01)$ (Table V). When we plotted $\mathrm{VO}_{2}$ max before and after training with propanolol as in Fig. 1, out of 9 patients, 2 showed insignificant increase in $\mathrm{VO}_{2}$ max, but 7 showed significant increase. The mean value was significantly increased as portrayed in Table II.

TABLE II

\begin{tabular}{|c|c|}
\hline $\begin{array}{l}\text { Before } \\
\text { raining } \bar{C}(P)\end{array}$ & $\begin{array}{c}\text { After } \\
\text { Training } \bar{C}(P)\end{array}$ \\
\hline $\begin{array}{ll}\text { F.T. } & 2.73 \\
\text { J.R. } & 2.00 \\
\text { E.F. } & 2.49 \\
\text { K.L. } & 2.25 \\
\text { R.Y. } & 1.74 \\
\text { B.W. } & 1.46 \\
\text { E.H. } & 1.67 \\
\text { J.H. } & 2.39 \\
\text { D.T. } & 1.87\end{array}$ & $\begin{array}{l}2.85 \\
2.65 \\
3.25 \\
2.36 \\
2.80 \\
1.54 \\
1.79 \\
3.34 \\
2.23\end{array}$ \\
\hline $\begin{array}{r}2.07 \\
\pm 0.42 \\
\pm 0.14\end{array}$ & $\begin{array}{r}2.53 \\
\pm 0.61 \\
\pm 0.20\end{array}$ \\
\hline
\end{tabular}

$(\mathbf{P}<.007)$

Table II Individual data of maximum oxygen uptake $\left(\mathrm{VO}_{2} \max \right)$ of the patients with coronary artery disease before and after endurance training with propanolol.

$p=$ probability, $(P)=$ propanolol

\section{.}

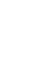

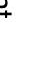


TABLE III

$\mathrm{VO}_{2}$ at Anaerobic Threshold (AT)

\begin{tabular}{|c|c|c|}
\hline \multicolumn{2}{|c|}{$\begin{array}{l}\text { Before Ex. } \\
\text { Training } \bar{c}(P)\end{array}$} & $\begin{array}{c}\text { After Ex. } \\
\text { Training } \bar{c}(P)\end{array}$ \\
\hline $\begin{array}{l}\text { Name } \\
\text { F.T. } \\
\text { J.R. } \\
\text { E.F. } \\
\text { K.L. } \\
\text { R.Y. } \\
\text { B.W. } \\
\text { E.H. } \\
\text { J.H. } \\
\text { D.T. }\end{array}$ & $\begin{array}{l}1.66 \\
1.15 \\
1.66 \\
1.53 \\
1.21 \\
1.14 \\
1.30 \\
1.83 \\
1.35\end{array}$ & $\begin{array}{l}1.92 \\
1.98 \\
2.26 \\
1.67 \\
1.83 \\
1.25 \\
1.36 \\
2.70 \\
1.75\end{array}$ \\
\hline $\begin{array}{l}\bar{x} \\
\text { SD } \\
\text { SEM }\end{array}$ & $\begin{aligned} & 1.43 \mathrm{~L} / \mathrm{Min} \\
\pm & 0.25 \\
\pm & 0.08\end{aligned}$ & $\begin{aligned} & 1.86 \text { L/Min } \\
\pm & 0.44 \\
\pm & 0.14\end{aligned}$ \\
\hline
\end{tabular}

$(P<.003)$

Table III Oxygen uptake at anaerobic threshold of the individual patients before and after exercise training with propanolol.

$p=$ probability,$(P)=$ propanolol

\section{TABLE IV}

Percentage of VO, Max at A.T.

Before Ex.
Training $\bar{c}(P)$ $\begin{gathered}\text { After Ex. } \\ \text { Training } \bar{c}(P)\end{gathered}$

\begin{tabular}{lcr} 
Name & & \\
F.T. & 60.1 & 67.3 \\
J.R. & 57.5 & 74.0 \\
E.F. & 66.1 & 69.0 \\
K.L. & 68.0 & 70.7 \\
R.Y. & 69.0 & 65.3 \\
B.W. & 78.0 & 81.0 \\
E.H. & 70.0 & 76.0 \\
J.H. & 76.0 & 81.0 \\
D.T. & 72.0 & 78.0 \\
\hline $\bar{x}$ & 68.2 & \\
SD & \pm 6.31 & 73.59 \\
SEM & \pm 2.23 & \pm 5.84 \\
& \multicolumn{2}{c}{ \pm}
\end{tabular}

$$
(\mathbf{P}<.001)
$$

Table IV The percentage of maximum oxygen uptake at anaerobic threshold before and after exercise training with $(P)$ of the individual patients.

$p=$ probability,$(P)=$ propanolo

\section{TABLE V}

$\underline{\mathrm{V}}$, Max/Body Wt. (ml/Kg)

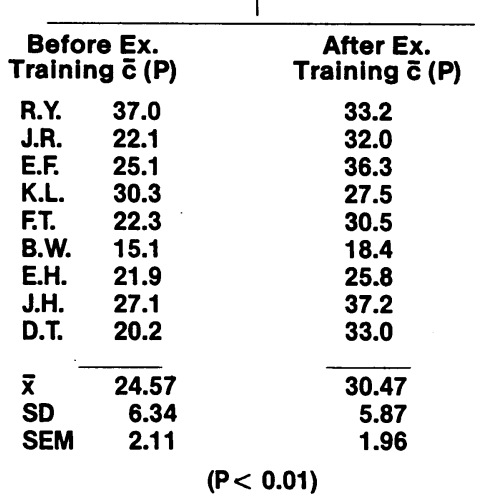

Table V The maximum oxygen uptake for $\mathrm{kg}$ body weight before and after exercise training with propanolol.

$p=$ probability,$(P)=$ propanolol

Figure 2 shows the individual and mean increase in $\mathrm{VO}_{2}$ at anaerobic threshold before and after training with propanolol. Figures 3 and 4 represent the individual and mean data of percentage of $\mathrm{VO}_{2}$ max and oxygen pulse at anaerobic threshold before and after training with propanolol.
MAX. OXYGEN UPTAKE $\left(\mathrm{VO}_{2}\right.$ MAX)

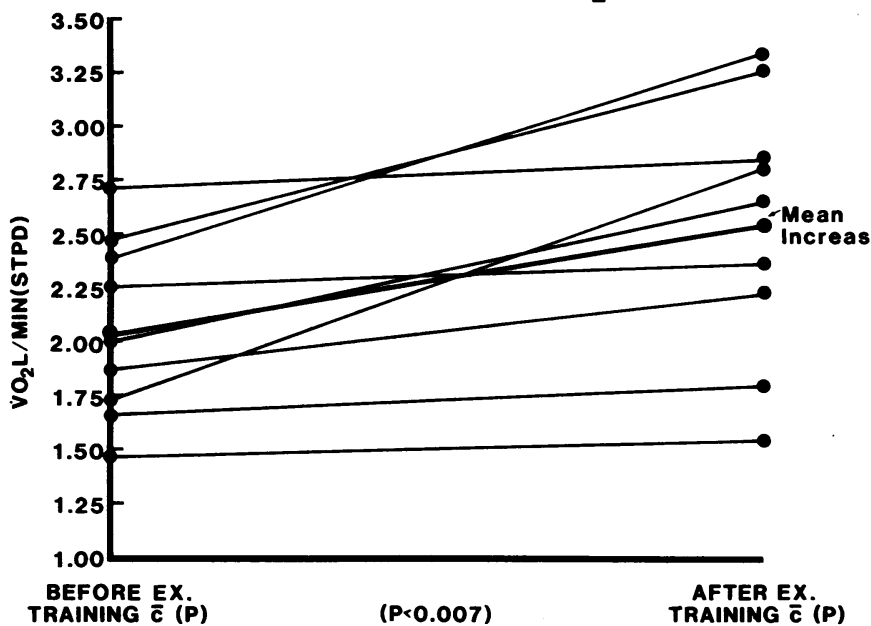

Fig. 1: Maximum oxygen uptake before and after exercise training of the patients. The mean increase is marked by heavy line.

$p=$ probability,$(P)=$ propanolol

$\nabla_{2}$ AT ANAEROBIC THRESHOLD (AT)

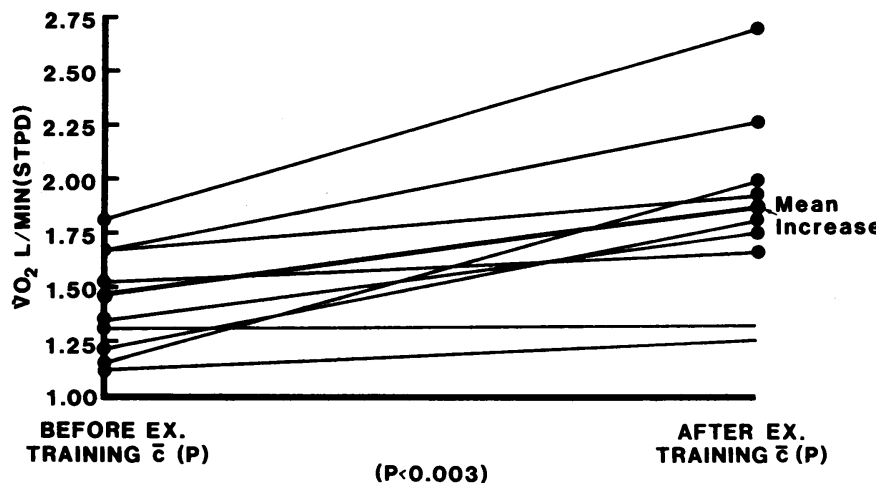

Fig. 2: Oxygen uptake at anaerobic threshold before and after endurance training with propanolol.

$p=$ probability,$(P)=$ propanolol

PERCENTAGE OF $\mathrm{VO}_{2}$ MAX. AT A T

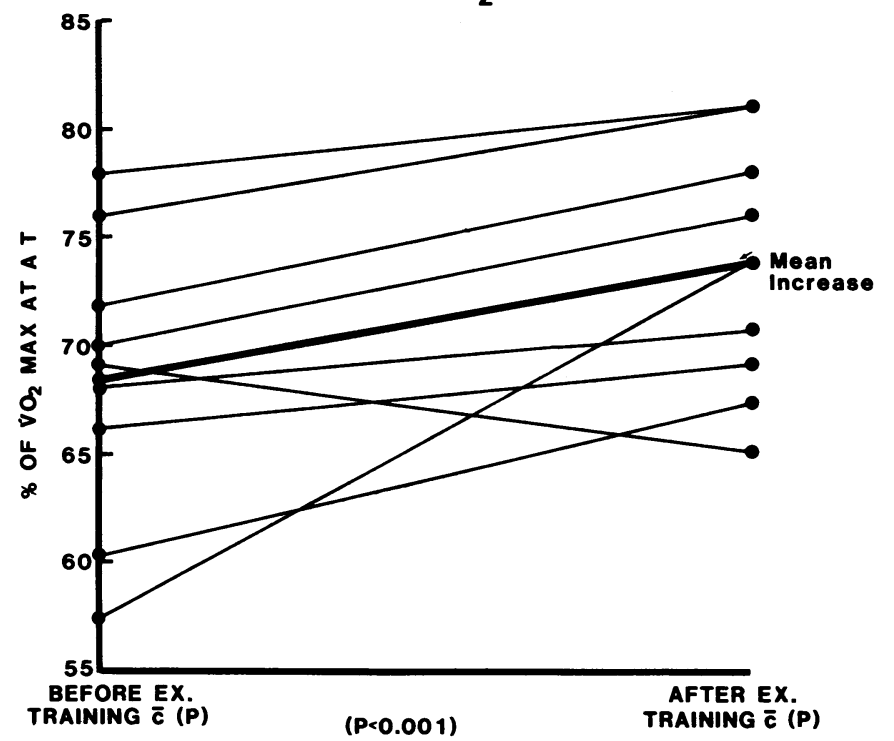

Fig. 3: Percentage of maximum oxygen uptake at anaerobic threshold. The heavy line denotes the mean increase of $\%$ of $\mathrm{VO}_{2}$ max before and after endurance training.

$p=$ probability, $(P)=$ propanolol 


\section{DISCUSSION}

The beta adrenergic blocking agent propanolol has been shown to induce effects that might influence the matching of ventilatory and circulatory responses to increased metabolic rate. Propanolol has been shown to reduce heart rate, cardiac output, mean arterial pressure and to increase central venous pressure in normal subjects (Epstein et al, 1965; Furberg and Schmalensee, 1968; Brown et al, 1976). It has also been responsible for lowering muscle lactate and carbon dioxide production during exercise in normals and patients with coronary artery disease as well (Twentyman et al, 1981). In addition, it has been associated with a decreased alactic exercise $\mathrm{O}_{2}$ debts, (Barnard and Foss, 1973) and favours an increased arteriovenous oxygen difference by reducing venous $\mathrm{O}_{2}$ content by increasing peripheral oxygen extraction (Detry et al, 1971).

We found that maximum oxygen uptake in patients on propanolol with coronary artery disease clearly increased after an exercise training programme. Bruce et al, 1979; Hossack et al, 1981; Sklar et al, 1982; Sable et al, 1982 and more recently Petersen et al, 1983 and Wilmore et al, 1983 observed no change, or a slight decrease in $\mathrm{VO}_{2}$ max in normal subjects after acute injection or oral administration of a beta blocker.

On the other hand, Obma et al, 1979; Pratt et al, 1981; Vanhees et al, 1982 and Gordon et al, 1983 found significant increase in $\mathrm{VO}_{2}$ max after training in coronary artery disease during long term beta adrenergic blockade. Our findings (Table II and Fig. 1) agree with the data of Gordon et al, 1983 and above groups. Of special interest was the alteration of anaerobic threshold after training. Davis et al, 1979, showed a significant increase in $\mathrm{VO}_{2}$ at anaerobic threshold (AT) on middle aged men after endurance training of 9 weeks duration with corresponding increase in $\mathrm{VO}_{2}$ max. They demonstrated that anaerobic threshold (AT) was profoundly influenced by endurance training on previously sedentary normal subjects. Our data (Table III, Fig. 2) on $\mathrm{VO}_{2}$ at $A T$ in patients with CAD show the similar results.

The percentage of $\mathrm{VO}_{2}$ max at $\mathrm{AT}$ in our patients increased from $68.2 \%$ to $73.6 \%$ after training. Wasserman et al, 1973 , found the AT in patients with congestive heart disease (CHD) Class II and Class III was approximately $30 \%$ to $40 \%$ of $\mathrm{VO}_{2}$ max. Matsumura et al, 1983; found the mean AT to be between $68 \%$ to $71 \%$ of $\mathrm{VO}_{2}$ max in patients with CHD Class I, II and III. The reasons for this difference might be that Wasserman et al, 1973, used the cycle ergometer for determin. ation of $\mathrm{VO}_{2} \max$ and $\mathrm{AT}$, and other authors used the treadmill. There is a significant difference in $\mathrm{VO}_{2} \max$ between different modalities of stress testing. Koyal et al, 1976 Hermansen et al, 1979; Åstrand and Rodahl, 1977, found nearly $20 \%$ difference in $\mathrm{VO}_{2}$ max between the cycle ergometer and treadmill. The mean $\mathrm{VO}_{2}$ max $/ \mathrm{kg}$ body weight (Table V, Fig. 4) increased significantly after exercise training.

In these patients the determinations may not be exactly the same $\mathrm{VO}_{2}$ max as in normal trained subjects where the $\mathrm{VO}_{2}$ plateaus at near max exercise inspite of increased work increments near termination of exercise due to fatigue and exhaustion. The $V_{2}$ max in patients with CAD may be symptom-limited and therefore, usually do not achieve the same physiologic plateau as in normal highly trained subjects.

Our criteria for noninvasive determination of anaerobic threshold was based upon the nonlinear increase of minute ventilation (VE), carbon dioxide production $\left(\mathrm{VCO}_{2}\right)$ and ventilatory equivalents for oxygen and carbon dioxide (Wasserman and Mcllroy, 1979; Wasserman et al, 1973; Koyal et al, 1976). Unlike studies with normal subjects, studies with patients with CAD the gas exchange ratio (RQ) is a less reliable noninvasive determinant of anaerobic threshold. It was
VO, MAX./BODY WT.

(ML/Kg)

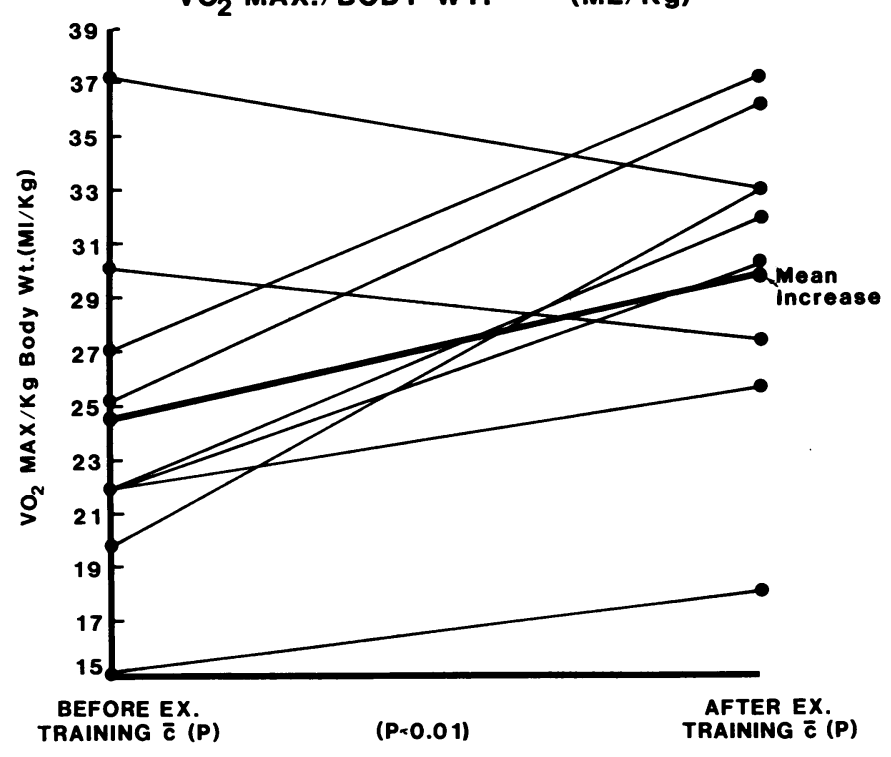

Fig. 4: Maximum oxygen uptake per $\mathrm{kg}$ body weight $(\mathrm{m} / \mathrm{kg})$ before and after exercise training. Heavy line indicates the mean increase. $p=$ probability,$(P)=$ propanolol

reported by Twentyman et al, 1981, that propanolol decreased $\mathrm{CO}_{2}$ production at the onset of exercise and early stages of incremental work due to reduced muscle perfusion as a consequence of decreased cardiac output as well as a direct effect on muscle blood supply. Cronin, 1967; Barnard and Foss, 1973, suggested that propanolol also inhibits glycolysis and lipolysis in working muscle and reduces the size of both lactic and alactic $\mathrm{O}_{2}$ debts of exercise. As a consequence of these factors, anaerobic metabolism is increased further as the rate of $\mathrm{CO}_{2}$ removal from the exercising muscle is delayed with lowering of gas exchange ratio during the onset and early stages of incremental exercise. During progressive work at the higher workloads anaerobic metabolism increases and the effects of increasing local metabolite concentrations supersede the effects of the beta blocker on muscle perfusion. The resultant increased blood flow facilitates carbon dioxide removal and, therefore, increases the gas exchange ratio.

Furburg and Schmalensee, 1968 and Reybrouck et al, 1977 demonstrated an increased arteriovenous oxygen difference with beta adrenergic blockade. The mechanism of venous $\mathrm{O}_{2}$ decrease was explained by reduced venous $\mathrm{O}_{2}$ content resulting from increased peripheral $\mathrm{O}_{2}$ extraction during exercise. Patients with CAD using long term beta blockers in addition to an exercise training programme might, we suggest, possibly augment an increased arterial $\mathrm{O}_{2}$ content and may thereby further widen an already increased $\mathrm{A}-\mathrm{VO}_{2}$ difference. This would, in turn, induce a higher $\mathrm{VO}_{2}$ max, longer exercise time, and shifting anaerobic threshold to higher workload. Our data on $\mathrm{VO}_{2} \max$ in CAD patients compare well with the findings of Obma et al, 1979; Pratt et al, 1981; Vanhees et al, 1982 and Gordon et al, 1983.

The oxygen pulse $\left(\mathrm{O}_{2} \mathrm{P}\right)$ is one of the important cardiorespiratory variables used for fitness classification. $\mathrm{O}_{2} \mathrm{P}$ is defined as the amount of $\mathrm{O}_{2}$ carried to the tissues in the blood by each left ventricular systole. It can be estimated by the ratio of oxygen uptake $\left(\mathrm{VO}_{2}\right)$ and heart rate $(\mathrm{HR})$. It is also equal to the product of stroke volume and arteriovenous oxygen $\left(A \cdot \mathrm{VO}_{2}\right)$ difference. We did not measure $\mathrm{A} \cdot \mathrm{VO}_{2}$ difference and cardiac output but we did estimate $\mathrm{O}_{2}$ pulse by measuring $\mathrm{VO}_{2}$ and $\mathrm{HR}$. Hanson et al, 1968; Åstrand and Rodahl, 1977; Wasserman et al, 1973 and Ellestad, 1981, postulated that $\mathrm{O}_{2} \mathrm{P}$ increased at a work rate below and above AT in middle aged normal subjects from rest. However, Twentyman et al, 1981, believed increased $\mathrm{A}-\mathrm{VO}_{2}$ difference is the major contributing factor for increased $\mathrm{VO}_{2}$ max and 
exercise tolerance in patients with CAD. Whatever the reason, our patients increased their $\mathrm{O}_{2}$ at anaerobic threshold after 4 months of a supervised training regime.

In summary, this study reveals an alteration of anaerobic threshold after exercise training in patients on propanolol which may be responsible for a significant increase in $\mathrm{VO}_{2}$ max. We suggest, tentatively that alteration of AT may also be due to an increase in stroke volume and perhaps also may be responsible for increased peripheral oxygen extraction.

\section{ACKNOWLEDGEMENTS}

The authors wish to express their appreciation to Ophelia Woodfork and Carol Fraser for their excellent secretarial assistance. We are also indebted to Ben Zinser, Public Relations Department, Memorial Medical Center for his assistance in the preparation of this manuscript.

\section{References}

Astrand P. O and Rodahl, K., 1977. Textbook of Work Physiology. (New York: McGraw-Hili).

Barnard, R. J. and Foss, M. L., 1973 "Oxygen debt: effect of beta adrenergic blockade on the lactacid and alactacid components". J.Appl Physiol, 34: 128-132.

Brown, H. V. Wasserman, K. and Whipp, B. J., 1976 "Effect of beta adrenergic blockade during exercise on ventilation and gas exchange". J.Appl.Physiol. 41: 886-892.

Bruce, R. A., Blackman, J. R., Jones, J. W. and Strait, G., 1963 "Exercise testing in adult normal subjects and cardiac patients". Pediatrics 32: 741-756.

Bruce, R. A., Hossack, K. R., Kusumi, F. and Clarke, L. J., 1979 "Acute effects of oral propanolol on hemodynamic responses to upright exercise". American Journal of Cardiology 44: 132-140.

Cronin, R. F. P. 1967 "Hemodynamics and metabolic effects of beta adrenergic blockade in exercising dogs". J.Appl.Physiol. 22: 211. 217.

Davis, J. A., Frank, M. H., Whipp, B. J. and Wasserman, K., 1979 "Anaerobic threshold alterations caused by endurance training in middle aged man". J.Appl.Physiol.Resp.Environ.Ex.Physiol. 46 (6): $1039-1046$

Detry, J., Rousseau, M., Vandenbroucke, G., Kusumi, M. S., Brasseur, L. A. and Bruce, R. A., 1971 "Increased arteriovenous oxygen difference after physical training in coronary heart disease". Circulation 44: 109-118.

Ellestad, M. H., 1981. Stress Testing: Principles and Practices. F. A. Davis Co., Philadelphia.

Epstein, S. E., Robinson, B. F., Kahler, R. L. and Braunwald, E., 1965 "Effects of beta adrenergic blockade on the cardiac response to maximal and submaximal exercise in man". J.Clin.Invest. 44: 17451753.

Furberg, C. and Schmalensee, G. V., 1968 "Beta adrenergic blockade and central circulation during exercise in sitting position in healthy subjects". Acta Physiol.Scand. 73: 435-446.
Gordon, N. F., Kruger, P. E. and Colliers, J. F., 1983 "Improved exercise ventilatory responses after training in coronary heart disease during long term beta adrenergic blockade". Am.J.Cardiol. 52: 755-758

Hanson, J. S., Tabakin, B. S., Levy, A. and Nedda, W., 1968 "Long term physical training and cardiovascular dynamics in middle aged men". Circulation 38: 783-799.

Hermansen, L.. Ekblom, B. and Saltin, B., 1979 “Cardiac output during submaximal and maximal treadmill bicycle exercise". J.Appl.Physiol. 29: 82.

Hossack, K. F., Bruce, R. A. and Kusumi, F., 1981 "Altered exercise ventilatory responses by apparent propanolol-diminished glucose metabolism: Implications concerning impaired physical training benefit in coronary patients". Am. Heart J. 102: 378-382.

Koyal, S. N. Whipp, B. J., Huntsman, D., Bray, G. A. and Wasserman, K. 1976 "Ventilatory responses to the metabolic acidosis of treadmill and cycle ergometry". J.Appl.Physiol. 40 (6): 864-867.

Matsumura, N., Nishyima, H., Kojima, S., Hashimoto, F., et al, 1983 "Determination of anaerobic threshold for assessment of functional state in patients with chronic heart failure". Circulation 68 (2): 360-367.

Obma, R. T. Wilson, P. K., Goebel, M. E. and Campbell, D. E., 1979 "Effect of a conditioning program in patients taking propanolol for angina pectoris". Cardiology 64: 365-371.

Petersen, E. S., Whipp, B. J., Davis, J. A., Huntsman, D. J., Brown, $H$. V and Wasserman, K 1983 "Effects of beta adrenergic blockade on ventilation and gas exchange during exercise in humans". J.Appl. Physiol.Resp.Environ.Ex.Physiol. 54 (5): 1306-1313.

Pratt, C. M., Welton, D. E., Squires, W. G., Kirby, T. E., Hartung, G. H. and Miller, R. R. 1981 "Demonstration of training effect during chronic beta adrenergic blockade in patients with coronary artery disease". Circulation 64: 1125-1129.

Reybrouck, T. Amery, A. and Bill, L., 1977 "Haemodynamic response to graded exercise after chronic beta adrenergic blockade". J.Appl. Physiol. 42: 133-135.

Sable, D. L., Brammell, H. L., Sheehan, M. W., Niew, A. S., Gerber, J. and Horwitz, L. D., 1982 "Alteration of exercise conditioning by beta adrenergic blockade"'. Circulation 65 (4).

Sklar, J. Johnston, G. D. Overlie, P. Genlier, J. G., Brammell, H. L. Gal J, and Niew, A. S, 1982 "The effects of a cardioselective (metoprolol) and beta adrenergic blocker on the response to dynamic exercise in normal man". Circulation 65 (5): 894-898.

Thadani, H. and Parker, J. O., 1979 "Propanolol in angina pectoris: Duration of improved exercise tolerance and circulatory effects after acute oral administration". Am.J.Cardiol. 44: 118-125.

Twentyman, O. P., Disley, A., Gribbin, H. R., Alberti, K. G. G. M. and Tatterfield, A. E., 1981 "Effect of beta adrenergic blockade on respiratory and metabolic responses to exercise". J.Appl.Physiol. 51: 788-793.

Vanhees, L., Fagard, R. and Amery, A., 1982 "Influence of beta adrenergic blockade on effects of physical training in patients with ischemic heart disease". Br. Heart J. 48: 33-38.

Wasserman, K. and Mcllroy, M. B., 1964 "Detecting the threshold of anaerobic metabolism". Am.J.Cardiol. 14: 844-852.

Wasserman, K., Whipp, B. J., Koyal, S. N. and Beaver, W. L. 1973 "Anaerobic threshold and respiratory gas exchange during exercise". J.Appl.Physiol. 35: 236-243.

Wasserman, K. and Whipp, B. J., 1975 "Exercise physiology in health and disease". Am.Rev.Respir.Dis. 112: 219-249.

Wilmore, J. H., Ewy, G. A., Morton, A. R., Stanforth, S. H., Constable, S. H., et al, 1983 "The effect of beta adrenergic blockade on submaximal and maximal exercise performance". J.Cardiol.Rehab. 3 (1): $30-36$ 